\title{
Designing of Lab-Scale Anaerobic Digester Equipped with Maxblend Impeller to Evaluate Effect of Mixing on Anaerobic Digestion
}

\author{
S. BUTA ${ }^{1}$, Z. SZAMOSI ${ }^{2}$, Z. SimÉNFALVI ${ }^{3}$ \\ ${ }^{1} \mathrm{MSc}$, doctorate student, ${ }^{2} \mathrm{PhD}$, assistant professor, ${ }^{3} \mathrm{PhD}$, associate professor \\ Institute of Energy Engineering and Chemical Machinery, University of Miskolc
}

\begin{abstract}
Operational parameters can be easily controlled at lab scale experiments for an anaerobic digestion process. Our aim is to design a lab-scale digester equipped with an impeller to investigate how the geometry of impeller and different mixing modes effect the biogas yield of digester. Further, the methods of measuring the gas volume, gas composition, mixing intensity, torque, temperature are discussed in this article. The assembling of 4 liters digester is described which can be operated at various operating parameters which control the anaerobic digestion process. Mixing is very important to enhance efficiency of an anaerobic digester. To attain mixing Maxblend impeller is used in this lab-scale digester due to its better performance for mixing and power consumption. Various design consideration has been described.
\end{abstract}

Key words: lab-scale digester, impeller, biogas, operation control

\section{Introduction}

Fabrication of a lab-scale digester is an important step to proceed the experimentation in lab for the different feed stock, because in full-scale plants the possibility of experiments is limited. Small scale digesters are of course very useful in prefatory examination of the susceptibility of various waste to biogas by optimizing the different operational parameters. The premier advantage of lab-scale digester over full scale digester is that fluctuation in the composition of input feed can be diminished, whereas it is rarely possible at large scale. However, it is difficult to anticipate the results from laboratory scale digester to full scale plant because many parameters like feeding mechanism, heating, stirring and gas recirculation can differ, but the aim of the lab-scale experiments is to make the foundation of scaling the lab into a full-scale plant. This paper describes an easily constructed and flexible design of digester.

Biogas is a trending source of renewable energy in modern world. Hence, there is great emphasis to improve the biogas production rates from biomass by developing the existing technology. Different types of shapes and sizes of digesters and impellers are used for methane production. However, deposition and stratification can result in failure of digester due to in efficient and insufficient mixing in a digester. Agitation of an anaerobic slurry is vital to accomplish, primarily, the supply of substrate to be distributed uniformly, secondly, to keep continuous contact between the microorganisms and 
sludge, tertiary, the concentration of end product and prohibited biological intermediates have to be maintained at minimum levels[1]. The mixing can boost the homogeneous distribution of nutrients and micro-organisms and can evade formation of surface crust and sedimentation [2].

Mixing in an anaerobic digester keeps the solid suspension and homogenizes the fresh substrate with active micro-organisms[3][4][5]. Impeller geometry and choice are significant to attain optimum hydrodynamic conditions and gas liquid mass transfer in the digester. Several studies had been published in last year's dealing with impact of mixing on biogas production rate using various designs of impellers and vessels[6][7][8]. Impellers are categorized as turbine impellers and paddle impellers and classified according to mixing regimes laminar or turbulent mixing. Due to lower transport of momentum in laminar flow the diameter of impeller approaches the diameter of tank. Impellers such as helical ribbon, anchor impeller, gate impeller are used for vessels where laminar flow is required. Various impeller design had been used by researchers at lab scale to enhance the biogas production rate. Considering the results and analysis of geometry of various impellers, max-blend impeller is selected to proceed research to study the effect of mixing on biogas production and methane content. Maxblend is new generation impeller which provides better mixing performance, low dissipation rates and simple geometry [9].The Maxblend impeller is efficient in the mixing of viscous fluids over a wide range of Reynolds numbers at lower energy dissipation. The main advantage of this impeller is precise control of mixing flow and uniform distribution of shear in the digester. Intermittent mixing is considered best for a stable anaerobic digestion. Various devices for controlling mixing parameters such as revolution per min (RPM), torque and mixing intervals are required to know the optimum mixing strategy for process.

\section{Apparatus design}

\subsection{Digester design}

The 4.5 liters flat bottom unbaffled cylindrical digester with working volume $3.5 \mathrm{l}$ was constructed from glassware. This digester will be a continuous type biogas digester, so the input and output ports should be constructed separately. Feed input and output ports were fabricated $70 \mathrm{~mm}$ below the top end of digester. All the joints were greased with silicon vacuum grease and the lid secured with flange clip. Impeller was fitted with $3 \mathrm{~mm}$ stainless steel shaft to the axel of motor. Pipe to collect gas was fixed on top lid (10 $\mathrm{mm}$ diameter and length $300 \mathrm{~mm}$ ). Various operational parameters are detailed in Table.1.

Table 1. Design operating parameters at laboratory scale

\begin{tabular}{|l|l|}
\hline \multicolumn{1}{|c|}{ Parameter } & \multicolumn{1}{c|}{ Design value or condition } \\
\hline Temperature $\left({ }^{\circ} \mathbf{C}\right)$ & Cow manure, corn stover \\
\hline Feed type & 15 \\
\hline Hydraulic retention time (HRT) & $5-10 \%$ \\
\hline Total solid content (TS) & To be calculated \\
\hline Organic loading rate $(\mathbf{O L R})$ & Once every day \\
\hline Feeding frequency & Intermittent \\
\hline Mixing type & $10-100$ RPM \\
\hline Mixing intensity & 15 min after feed, twice a day \\
\hline Mixing time & \\
\hline
\end{tabular}




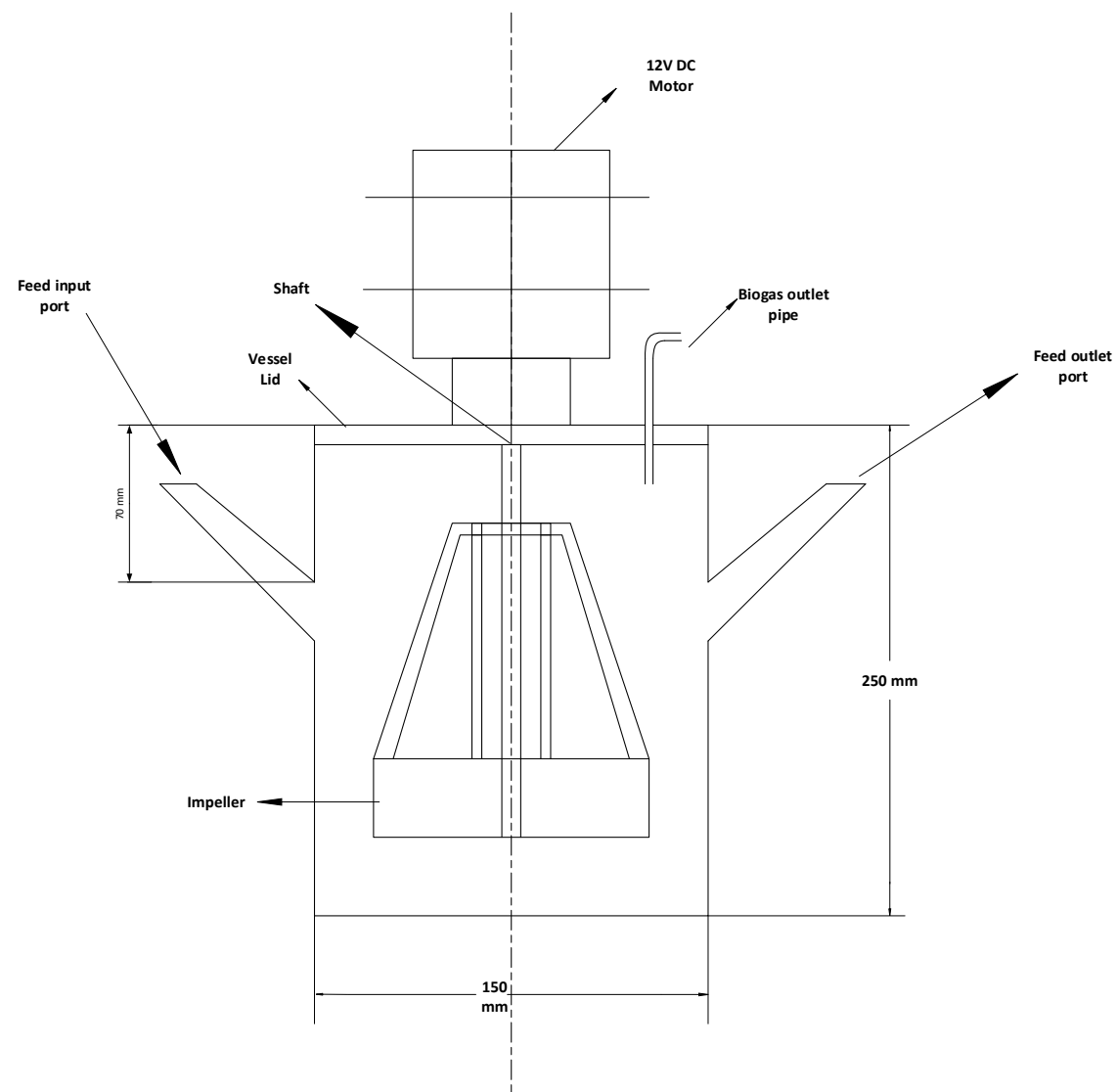

Figure 1. Schematic diagram of labscale anaerobic digester

\subsection{Chemical and physical monitoring}

There are numerous parameters which have to be analyzed on regular intervals to know the operational stability and performance of digester. As discussed earlier the mixing will be intermittent during the process at particular mixing speed because continuous mixing is not favorable for microorganisms during the digestion process[10]. Effect of mixing can be observed by measurement of different characteristic parameters. The digester influent and effluent will be sampled twice per week for analysis of $\mathrm{pH}$, total and soluble chemical oxygen demand (COD, sCOD) and volatile fatty acids (VAF's).

Table 2. Schematic overview of experimental duration and relative timings of biomass sampling for lab scale digester.

\begin{tabular}{|l|l|l|}
\hline Parameter & Measurement device & Sampling frequency \\
\hline pH influent and effluent & pH meter & Bi-weekly \\
\hline Chemical oxygen demand (COD) & $\begin{array}{l}\text { PeCOD L100 Laboratory/ } \\
\text { Portable COD - Chemical Oxygen } \\
\text { Demand Analyser } \\
\text { Biogas production rate (BPR) }\end{array}$ & Bi-weekly \\
\hline Methane content in biogas & Gas chromatography & Bi-weekly \\
\hline Temperature & Thermometer & Continuous \\
\hline Volatile fatty acids (VFA's) & Liquid chromatography & Bi-weekly \\
\hline
\end{tabular}




\section{Impeller design}

\subsection{Material selection}

Impeller was made from stainless steel sheet. Stainless steel was selected for this purpose because of its properties like good weldability, anticorrosive nature and light weight. The shaft and impeller should be anticorrosive because the desired purpose of use of agitator includes submerging it in liquid solution of feed material.

\subsection{Impeller geometry}

Impeller geometry plays significant role in attaining mixing homogeneity, mixing time and power consumption. Three are various parameters in maxblend impeller like number of grids, bottom clearance, grid size and paddle size. The bottom paddle is responsible for pumping effect and the upper grid is for dispersion[11]. The wedge shape of grid is favorable for viscous applications and straight is for turbulent regime. From the literature it has been observed that bottom clearance plays a significant role in mixing efficiency and power consumption[12]. The drop in power consumption due to increase in the bottom clearance is quite significant and similar trend was observed for shear constant by varying bottom angle[13].The impeller is mounted in the digester with very small clearance from the bottom wall and the lower edge of impeller.

Further, the paddle of impeller is introduced with the holes because this type of geometry reduces the segregated zones at the bottom of tank at expense of very slight increase in power consumption and mixing time[14]. Dimensions of various parameters are detailed in table 3.

Table 3. Geometrical dimensions of Maxblend impeller

\begin{tabular}{c|cc}
\multicolumn{1}{c}{ Parameter } & Dimensional formulae & Dimension $(\mathbf{m m})$ \\
\hline Digester diameter $(D)$ & $\mathrm{D}$ & 150 \\
Bottom clearance $(c)$ & $0.1 \mathrm{D}$ & 15 \\
Impeller blade height $(h)$ & $1 \mathrm{D}$ & 150 \\
Impeller blade diameter $(d)$ & $0.6 \mathrm{D}$ & 90 \\
Shaft diameter $\left(d_{s}\right)$ & $0.1 \mathrm{D}$ & 15 \\
The paddle height $\left(h_{1}\right)$ & $0.33 \mathrm{D}$ & 50 \\
The grid height $\left(h_{2}\right)$ & $0.46 \mathrm{D}$ & 70 \\
The grid diameter $\left(d_{1}\right)$ & $0.45 \mathrm{D}$ & 67.5
\end{tabular}


International Journal of Engineering and Management Sciences (IJEMS) Vol. 4. (2019). No. 1

DOI: 10.21791/IJEMS.2019.1.50.

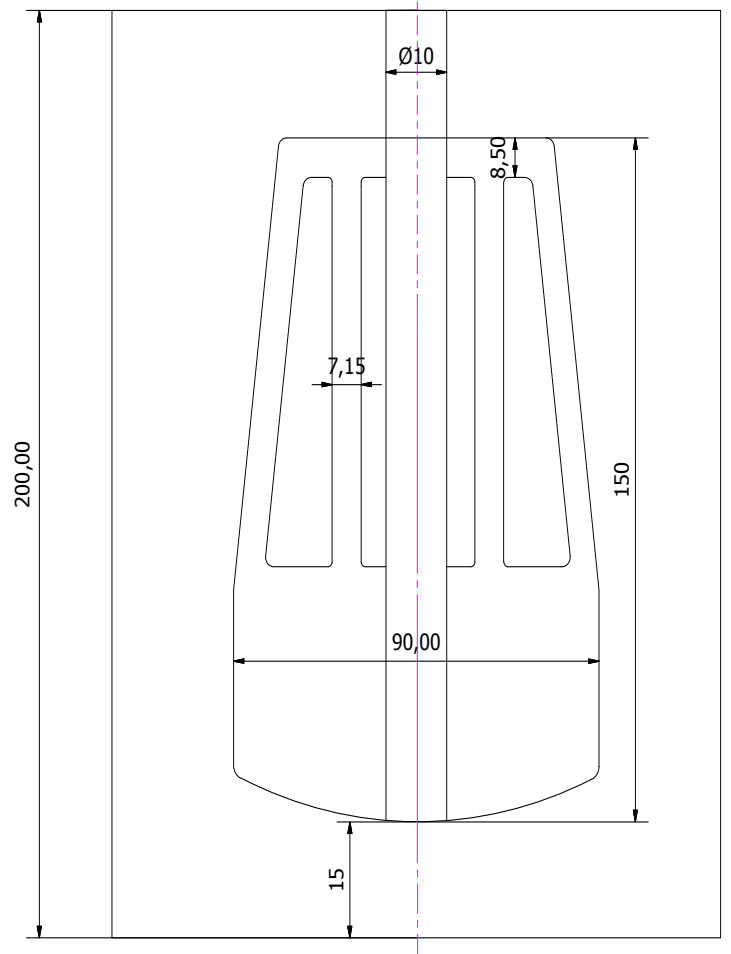

Figure 2. 2-D Geometrical design of Maxblend Impeller.

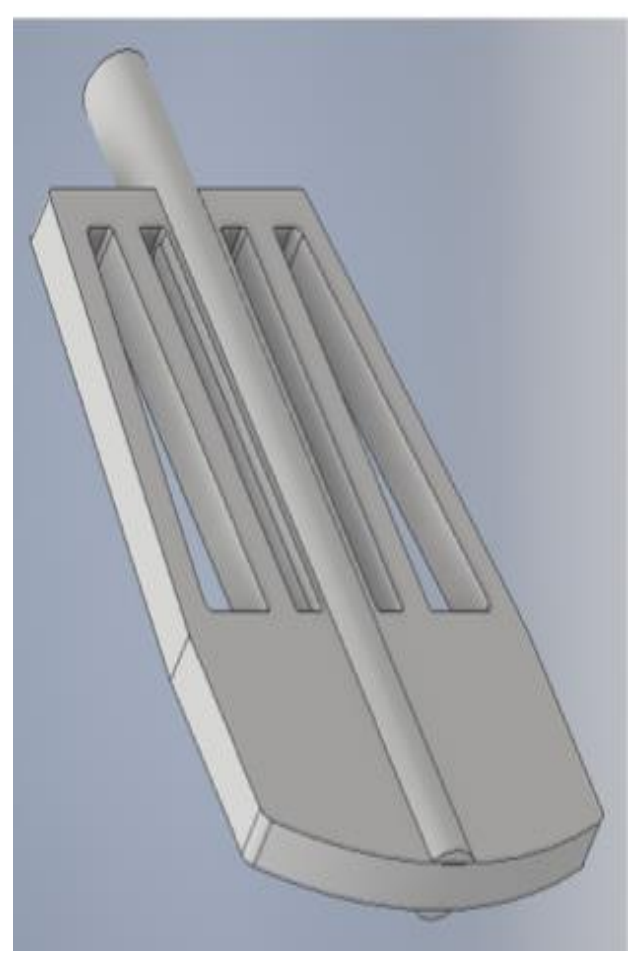

Figure 3. 3-D design of Maxblend Impeller
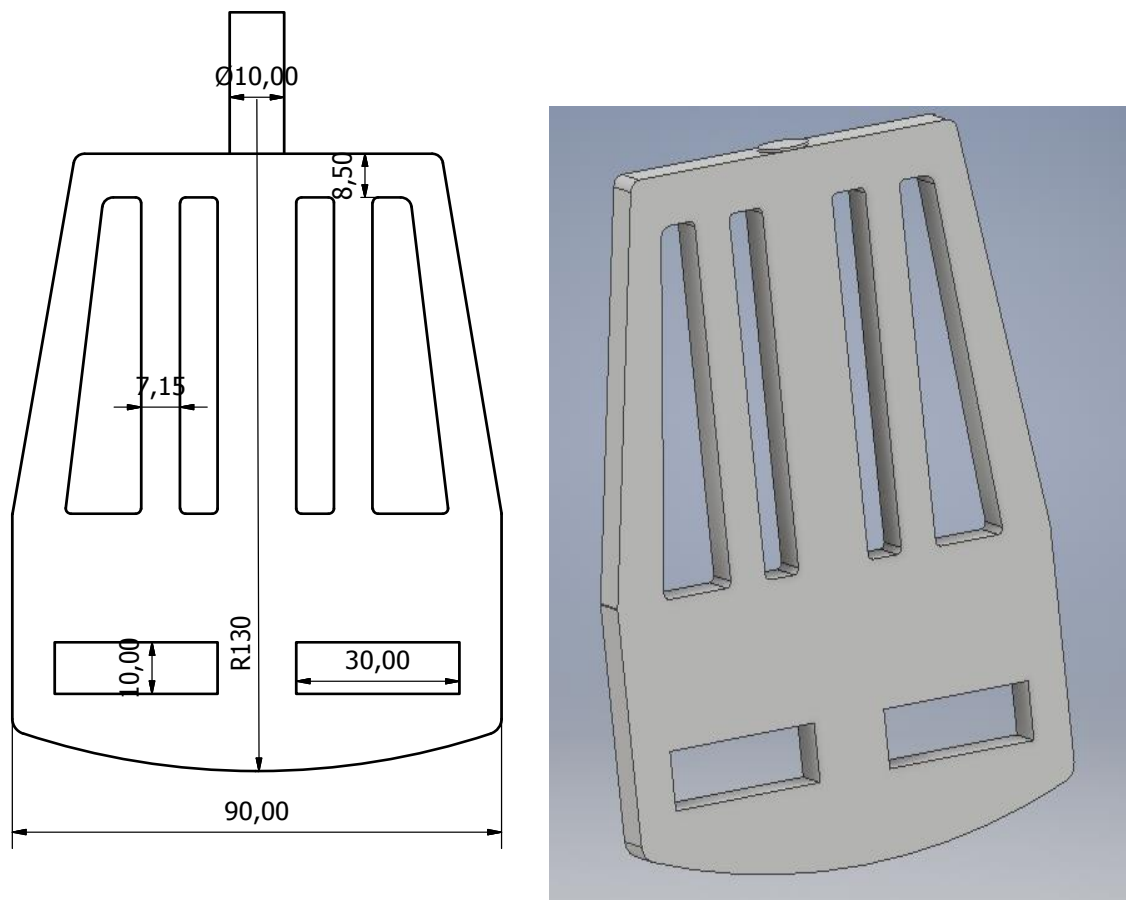

Figure 4. 3D design of Maxblend Impeller with holes. Figure 5. Geometrical design of Maxblend Impeller with holes 


\subsection{Motor characteristics}

The impellers are actuated by a variable speed motor allowing the rotational speed to vary between 1 to 120 RPM. The power consumption is derived from the torque produced and the rotational speed measurements.

\subsection{Theoretical considerations}

Slurry for the digester will consist of corn stover and cattle manure. Rheological properties of slurry should be known to evaluate the mixing characteristics of impeller and its effect on biogas production. The rheology can be described by Herchel Bulkley model[15]:

$$
\tau=\tau_{y}+K \cdot \dot{y}^{n}
$$

Where $\tau_{y}$ is the yield stress $(\mathrm{Pa}), K$ is consistency index $(\mathrm{Pa} \mathrm{s}), \dot{y}$ is shear rate $\left(\mathrm{s}^{-1}\right)$ and $n$ is flow index. According to Metzner and Otto's correlation, the average shear rate can be related to impeller speed $(N)$ :

$$
\dot{y}_{a v g}=K_{s} N
$$

Where $K_{s}$ is consistency index of the impeller $\left(\mathrm{Pa} \mathrm{s}^{\mathrm{n}}\right), y_{\text {avg }}$ is average shear rate $\left(\mathrm{s}^{-1}\right)$.

The shear rate can be used to evaluate the apparent viscosity $(\eta)$ of the slurry as:

$$
\eta=\frac{\tau}{\dot{y}_{\text {avg }}}=\frac{\tau}{K_{s} \cdot N}=\left\{\tau_{y}+K \cdot\left(K_{s} \cdot N\right)^{n}\right\} / K_{S} \cdot N
$$

Power $(P)$ drawn by an impeller can be calculated as:

$$
P=2 \cdot \pi \cdot N \cdot M
$$

Where $M$ is net torque (N. m).

The Power Number is a dimensionless number that relates Power with important aspects of an agitation vessel. The power number $N p$ is determined by the following equation:

$$
N p=P / \rho \cdot N^{3} \cdot D^{5}
$$

\section{Biogas monitoring}

\subsection{Gas measurement apparatus}

Biogas production will be recorded continuous. Since gases have small densities, it is usually not practical to collect gas and find its mass. For the gases that are practically not soluble in water, it is possible to collect the produced gas by displacement of water from a container. This method is very simple economical and work for longer period of time without maintenance. Biogas is produced by 
anaerobic digester on daily basis. Water displacement method will be used to measure the daily gas production. In this method the volume of water displaced by gas signifies the volume of biogas produced by the digester. There can occur some errors due to fluctuation of atmospheric temperature so it is very important to record the changes.

For this purpose, two cylindrical vessels were used (6l each). Digester and the vessels are connected in series by $10 \mathrm{~mm}$ pipe. Cylinder 1 is fully filled with water and is connected to digester to receive biogas. As the pressure increases in digester biogas enters the cylinder. Further, the increases of pressure head in cylinder the water is pushed to cylinder 2 and collected there. The volume of water entering the cylinder 2 can be measured and volume of gas can be determined.

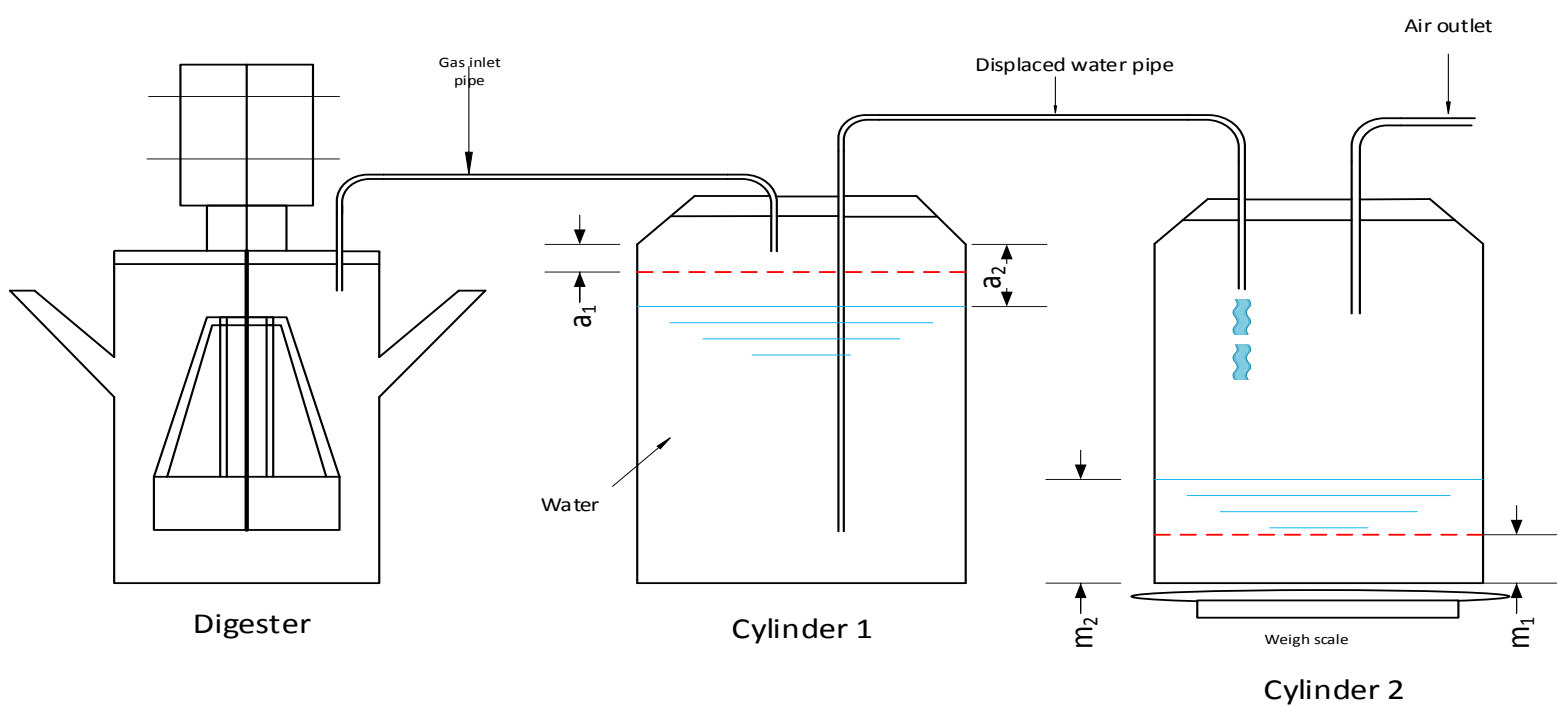

Figure 6. Schematic diagram of biogas volume measurement apparatus.

The volume of gas collected, and the gas laws can be used to calculate the number of moles of gas collected. The experimental arrangement demonstrates one minor complication. The gas pressure inside the cylinder 1 is sum of biogas pressure and water vapours. The water in the cylinder will reach an equilibrium state where the number of molecules leaving the surface will be same as the number returning. According to Dalton's law of partial pressure:

$$
P_{T}=P_{b i o}+P_{H_{2} O}
$$

Where $P_{T}$ is total pressure of cylinder $(\mathrm{Pa}), P_{b i o}$ is pressure of biogas $(\mathrm{Pa}), P_{\mathrm{H}_{2} \mathrm{O}}$ is pressure of water vapours $(\mathrm{Pa})$

From above equation $\mathrm{P}_{\text {bio }}$ can be easily calculated as

$$
P_{\mathrm{H}_{2} \mathrm{O}}=6.1121 \exp \left\{\left(18.678-\frac{T_{c}}{234.5}\right) \times \frac{T_{c}}{257.14+T_{c}}\right\}
$$

Where $T c$ is temperature of gas in degree Celsius

Equation of gas volume calculation by weighing displaced water from cylinder 2

$$
V_{o}=\frac{T_{o} \cdot\left(m_{b}-m_{a}\right)}{T \cdot P_{o} \cdot \rho}\left[\left[P_{T}-P_{H_{2} O}+\rho \cdot g\left(a_{1}+a_{2}+\frac{V_{a}}{A}\right)\right]\right.
$$


Here $V o$ is volume of gas produced at standard temperature and pressure, To is standard temperature, $a$ and $b$ represents height of gas and liquid respectively, $m$ is mass of liquid measured, 1 and 2 represent initial and final height, $\rho$ represents density of water, A is area of cross section, $\mathrm{g}$ is acceleration due to gravity.

\subsection{Gas composition}

Biogas composition will be analyzed twice a week is gas chromatography. For this purpose Dani Master Gas chromatography (GC) will be used. The GC will analyse the $\mathrm{CO}, \mathrm{CO}_{2}, \mathrm{H}_{2}, \mathrm{H}_{2} \mathrm{~S}, \mathrm{CH}_{4}, \mathrm{C}_{2} \mathrm{H}_{6}, \mathrm{C}_{2} \mathrm{H}_{4}$, $\mathrm{O}_{2}$ and $\mathrm{N}_{2}$ content in biogas. Volume of each sample will be $20-30 \mathrm{ml}$ per analysis. The time of an analysis is $12 \mathrm{~min}$. Detals of Dani Master GC are given below in the table 4.

Table 4. Detailed specification of Gas chromatography

\begin{tabular}{|c|c|}
\hline Chromatograph type & Dani Master GC \\
\hline Detector & Thermal Conductivity Detector (TCD) \\
\hline Temperature & $110^{\circ} \mathrm{C}$ \\
\hline Voltage & $4 \mathrm{~V}$ \\
\hline Signal range & 1 \\
\hline Sample injection & Loop, $200 \mu \mathrm{l}$ \\
\hline Injector & S/SL \\
\hline Mode & Splitless \\
\hline Split purge & $10 \mathrm{ml} / \mathrm{min}$ \\
\hline Temperature & $40^{\circ} \mathrm{C}$ \\
\hline Pressure control & $400 \mathrm{kPa}$ \\
\hline Carrier gas & Helium 6.0 \\
\hline First column (Q-Bond 1 ) & Restek RT-Q-Bond (Fused Silica PLOT) \\
\hline $\begin{array}{l}\text { Length } \mathrm{x} \text { Inner diameter x Film } \\
\text { thickness }\end{array}$ & $30 \mathrm{~m} \times 0.32 \mathrm{~mm} \times 10 \mu \mathrm{m}$ \\
\hline Second column (Q-Bond 2) & Restek RT-Q-bond (Fused Silica PLOT) \\
\hline $\begin{array}{l}\text { Length } x \text { Inner diameter x Film } \\
\text { thickness }\end{array}$ & $15 \mathrm{~m} \times 0.53 \mathrm{~mm} \times 20 \mu \mathrm{m}$ \\
\hline Third column & Restek RT-Msieve 5A (Fused Silica PLOT) \\
\hline $\begin{array}{l}\text { Length x Inner diameter x Film } \\
\text { thickness }\end{array}$ & $30 \mathrm{~m} \times 0.53 \mathrm{~mm} \times 50 \mu \mathrm{m}$ \\
\hline \multicolumn{2}{|l|}{ Configuration of column with software* } \\
\hline $\begin{array}{l}\text { Length } \mathrm{x} \text { Inner diameter } \mathrm{x} \text { Film } \\
\text { thickness }\end{array}$ & $45 \mathrm{~m} \times 0.32 \mathrm{~mm} \times 20 \mu \mathrm{m}$ \\
\hline Oven temperature & $36^{\circ} \mathrm{C}$ \\
\hline Method events & Times of switching the valve \\
\hline flow in all three columns & $0-1.80 \min$ \\
\hline flow in only the Q-Bond column & $1.80-5.70 \mathrm{~min}$ \\
\hline flow in all three columns & $5.70-12.5 \mathrm{~min}$ \\
\hline Aux gas & Nitrogen 5.0 \\
\hline Aux gas pressure & $270 \mathrm{kPa}$ \\
\hline Cycle time & $12 \min$ \\
\hline Evaluation software & Clarity 3.0.6.589 \\
\hline
\end{tabular}




\section{Conclusion}

Lab-scale digester was successfully designed with low cost and effective design to reduce the experimental and measurement errors. Laboratory scale idealization strongly influence each of digester performance, microbial community structure and spatial distribution of substrate and microorganisms. The design is very flexible as the agitator can be easily modified for various other experiments.

\section{Acknowledgement}

"The described article/presentation/study was carried out as part of the EFOP-3.6.1-16-2016-00011 "Younger and Renewing University - Innovative Knowledge City - institutional development of the University of Miskolc aiming at intelligent specialisation" project implemented in the framework of the Széchenyi 2020 program. The realization of this project is supported by the European Union, cofinanced by the European Social Fund."

\section{References}

[1] M. H. Gerardi (2003) The Microbiology of Anaerobic Digesters. John Wiley \& Sons.

[2] A. Kowalczyk - E. Harnisch - S. Schwede - M. Gerber - R. Span (2013) Different mixing modes for biogas plants using energy crops. Appl. Energy. 112 pp. 465-472.

[3] Z. Tian - D. Chauliac - P. Pullammanappallil (2013) Comparison of non-agitated and agitated batch, thermophilic anaerobic digestion of sugarbeet tailings. Bioresour. Technol. 129 pp. 411420.

[4] C. Rojas - S. Fang - F. Uhlenhut - A. Borchert - I. Stein - M. Schlaak (2010) Stirring and biomass starter influences the anaerobic digestion of different substrates for biogas production. Eng. Life Sci. 10 (4) pp. 339-347.

[5] I. D. Kariyama - X. Zhai - B. Wu (2018) Influence of mixing on anaerobic digestion efficiency in stirred tank digesters: A review. Water Res. 143 pp. 503-517.

[6] M. Terashima et al. (2009) CFD simulation of mixing in anaerobic digesters. Bioresour. Technol., 100 (7) pp. 2228-2233.

[7] A. Lebranchu et al. (2017) Impact of shear stress and impeller design on the production of biogas in anaerobic digesters. Bioresour. Technol. 245 (June) pp. 1139-1147.

[8] B. Wu (2010) CFD simulation of mixing in egg-shaped anaerobic digesters. Water Res. 44 (5) pp. 1507-1519.

[9] H. Ameur (2015) Energy efficiency of different impellers in stirred tank reactors. Energy. 93 pp. 1980-1988.

[10] Z. Tian - L. Cabrol - G. Ruiz-Filippi - P. Pullammanappallil (2014)Microbial ecology in anaerobic digestion at agitated and non-agitated conditions. PLoS One. 9 (10). 
[11] A. Fontaine - Y. Guntzburger - F. Bertrand - L. Fradette - M. C. Heuzey (2013) Experimental investigation of the flow dynamics of rheologically complex fluids in a Maxblend impeller system using PIV. Chem. Eng. Res. Des. 91 (1) pp. 7-17.

[12] C. Devals - M. Heniche - K. Takenaka - P. A. Tanguy (2008) CFD analysis of several design parameters affecting the performance of the Maxblend impeller. Comput. Chem. Eng. 32 (8) pp. 1831-1841.

[13] P. A. Tanguy - K. Takenaka (2005) Power and Mixing Time Study Involving a Maxblend W Impeller with Viscous Newtonian and Non-Newtonian Fluids. Chem. Eng. Res. Des.. 85. pp. 1514-1523.

[14] Y. Guntzburger - L. Fradette - M. Farhat - M. Heniche - P. A. Tanguy - K. Takenaka (2009) Effect of the geometry on the performance of the Maxblend impeller with viscous Newtonian fluids. ASIAPACIFIC J. Chem. Eng. 4 pp. 528-536.

[15] 0. Metzner B (1994) Rheology: priciples, measurements and applications. pp. 47-9. 